\title{
IDEJA PRIRODNOSTI - TEMELJNI PRINCIP DIDAKTIČKOG SISTEMA J. A. KOMENSKOG ${ }^{2}$ (povodom 350 godina od smrti velikana pedagoške misli)
}

\author{
Apstrakt
}

U radu autor osvetljava osnovnu ideju, koja se nalazi u temelju didaktičkog sistema J. A. Komenskog, a to je ideja prirodnosti. Nju je Komenski izrazio čuvenom formulacijom omnia sponte fluan, absit violenitia rebus (u slobodnom prevodu: neka sve teče spontano, bez nasilja). Ideja prirodnosti ima svoje korene u Komenskijevom panharmonijskom shvatanju celokupne stvarnosti i njegovim svepopravnim nastojanjima: popravljanju svakog pojedinca i celokupnog društva pomoću istinskog, pansofijskog obrazovanja. Komenski odbacuje svaki oblik nasilja, uključujući ono u didaktici-veštini poučavanja svih u svemu. Obrazovanje i učenje su sastavni deo celokupnog prirodnog toka, a učitelj je sluga, a ne gospodar prirode. Uskladu s tim, dobra metoda je prirodna, nenasilna, radosna. U radu autor osvetljava dublje kulturno-istorijske korene ovakvih Komenskijevih shvatanja (husitska tradicija, ali i uticaji F.Bekona, T. Kampanele, M. F. Kvintilijana) i ukazuje na svežinu i aktuelnu vrednost Komenskijevih didaktičkih pogleda, koji su uticali na reformnu i progresivističku pedagogiju 20. veka, ali i dan-danas deluju inspirativno u naučnim i praktičnim traganjima za humanim pristupom u nastavi i učenju, koji poštuje i podstiče samoodređenje, samoaktivnost, slobodu i kreativnost dece.

Ključne reči: Komenski, prirodnost, didaktika, reformna pedagogija, dete.

\section{Opšti kontekst - svepopravni okviri Komenskijeve didaktike}

Čitav život J. A. Komenskog, počevši najranijim detinjstvom, bio je obeležen nasiljem: ratovima, upadima vojski, epidemijama kuge, smrću najbližih, paljevinom,

\footnotetext{
${ }^{1}$ zoroslav.spevak@ff.uns.ac.rs.

${ }^{2}$ Rad je nastao u okviru projekta „Kvalitet obrazovnog sistema Srbije u evropskoj perspektivi“ KOSSEP br. 179010, koji finansira Ministarstvo prosvete, nauke i tehnološkog razvoja Republike Srbije.
} 
progonima, bežanjem, egzilom, lutanjem bez doma i stalnog boravka. Samo sedam godina tokom čitavog 17. veka u Evropi proteklo je bez ratova. To je bio taj „krvavi lavirint" iz kojeg je Komenski tokom celog svog života uporno tražio izlaz. Uprkos tome, ili upravo zbog toga, izgradio je (prvenstveno na shvatanjima N. Kuzanskog) filozofski zasnovano uverenje o panharmonijskom uređenju sveta:fundamentum rerum omnium harmonia est (osnova svih stvari je harmonija). Uprkos površinskoj zapenušanosti, protivrečnosti i konfliktnosti pojavne stvarnosti (coincidentia opositorum), u dubini te stvarnosti zapravo nema definitivnih opozicija i raskola: sve je unutrašnje spojeno, osuđeno na saglasje, obezbeđeno delovanjem duše sveta (animae mundi), koja harmonizuje i spaja ljubavlju (Spevak, 2003). Upravo za tom dubinskom (pan) harmonijom traga Komenski, upravo njome (a pomoću pansofije i didaktike) želi da obasja misao ljudi (prvenstveno dece) i da čovečanstvo kao celinu izvede iz krvavog lavirinta na put svetlosti.

Njegova didaktika, kao umetnost poučavanja svih u svemu, takođe je instrument u toj nameri. Ceo problem svetskih sukoba Komenski posmatra prvenstveno sub spaetie educatinonis (sa stanovišta obrazovanja), a kao neko ko se drži Aristotelovog kreda da je „zadatak mudrog da uređuje“ on pokušava da uredi znanje (pansofija je izraz tog nastojanja, shvaćena ne kao enciklopedija, kao gomila naslaganog drveta, nego upravo kao znanje o dubinskom, harmonijskom uređenju sveta - kao drvo mudrosti), te da pronađe ars (veštinu), kako da to pansofijsko znanje posreduje na brz, pouzdan i prijatan način onima koji su pravi nosioci popravljanja sveta, a to su deca. Jer deca su, ističe Komenski u „Velikoj didaktici“ „živa slika živog Boga, ona su uzor bezazlenosti, blagosti, poniznosti, čistote, poslušnosti itd."(Komenski, 1954: 6), ona su odraslima učitelji, njihova dela uzori. Odojčad su „učenici pansofije“ (Komenský, 1992: 258), a „celokupna nada sveta u opšte popravljanje stvari zavisi od prvog vaspitanja“" (Komenský, 1992: 79). Greške prvog vaspitanja prate nas tokom celog života, a glavna odbrana čovečanstva je u kolevci (Spevak,2003).

Pansofija i didaktika se ne mogu odvajati, one imaju zajednički koren i svrhu. Komenski svojim pansofijskim delima (gde spada i „Čulni svet u slikama“ - pansofijsko delo za decu predškolskog uzrasta), nastoji da celokupnu složenost uređenja sveta i univerzuma svede na jednostavne, sasvim shvatljive, osnovne pojmove i odnose (takoreći azbuku stvarnosti), koje bi kroz pojedinosti svedočile o celini sveta (mikrokosmos-makrokosmos), u kome je sve povezano sa svime i svaki delić stvarnosti svedoči o njenoj sveukupnosti. Takvo znanje je put do ozdravljenja i harmonizacije čovečanstva. Zato ono mora da bude posredovano deci na najbolji, najefikasniji i najprijatniji način - pomoću pouzdane, efikasne i prijatne (nenasilne) metode. Didaktička veština (ars didaktica) brzog, pouzdanog i prijatnog poučavanja, dakle, ima ovaj pansofijski i panharmonijski temelj i cilj, a reforma didaktike (pojam koji je Komenski preuzeo od nemačkog pedagoga W. Ratkea) uključena je u reformu svakog pojedinca i čitavog čovečanstva. Jer, kako ističe Komenski na jednom mestu: „Mi, celo ljudsko pokolenje, jedno smo potomstvo, jedna krv, jedna porodica, jedan dom“(Spevak, 2003: 186). 


\section{Ideja prirodnosti kao temelj didaktike. Poštovanje deteta. Princip igre.}

Komenski odbacuje svako nasilje, u svim segmentima postojanja. U ratovima i nasilju vidi samo destrukciju, nesreću i razaranje ljudskosti i morala (Spevak, 2003). Ako čovečanstvo želi da izađe iz „krvavog lavirinta“ mora se okrenuti istinskom (pansofijskom) znanju i onima koji jedino mogu ostvariti ideju (pan)harmonije na ovom svetu - deci. To je moguće ostvariti, ubeđen je Komenski, pomoću didaktike, koja omogućava da taj proces protekne brzo, pouzdano i na prijatan način, koja je dakle zasnovana na ideji prirodnosti. Na jednoj strani radi se o tome kako funkcioniše priroda sama, a njene modalitete, kada ih upoznamo, možemo onda da primenimo na sve slojeve stvarnosti, pa i na samu ljudsku delatnost, pa i na didaktiku kao veštinu. To je ideja paralelizma i sinkretičke metode, koja se sastoji u uverenju da je stvarnost jedinstvena, povezana i usaglašena, te ako njene principe upoznamo u jednom njenom sloju - recimo na nivou prirode - možemo zaključiti da ti isti principi važe i funkcionišu i u ostalim segmentima sveukupne stvarnosti. Na drugoj strani, radi se o prirodi čoveka, pa i deteta, koju Komenski, za razliku od dominantnog srednjevekovnog shvatanja na Zapadu (stigma praroditeljskog greha), pa i shvatanja reformacije 16. i 17. veka, sagledava i tumači u ključu antropološkog optimizma - kao pozitivnu, koja je aktivna, teži samorazvoju i (samo)ostvarenju u duhu humanistički vrednih postignuća.

Komenski u svoje vreme nije imao na raspolaganju nikakvu stvarnu naučnu disciplinu, niti se sam bavio istraživanjem prirode, ali je za temelj i ideju vodilju svoje didaktike upotrebio filozofsku koncepciju panharmonije i univerzalnog paralelizma, odnosno sinkretičku metodu, koja mu je omogućila da veštinu veštačkog podučavanja izvede iz poslednjih dubina prirode (Patočka, 1981). Sinkretičkom metodom Komenski je zapravo formulisao prirodnu metodu veštačkog poučavanja. Didaktika, kao veština, mora pre svega da ima jasno utvrđen cilj. Taj cilj mora da bude izveden iz prirode sveta, prirode čoveka i prirode poučavanja. Paralelizam između prirode i veština dovela je Komenskog do pronalaska veštine nad veštinama. tj. didaktičke veštine poučavanja svih u svemu, koja je izvedena ne iz empirijskih uvida, nego iz pretpostavljenih prazakonitosti stvari. Posmatranjem prirode čovek može da spozna večne ideje i norme svetskog uređenja. Ovaj postupak jasno je vidljiv - i dovoljno poznat - iz „Velike didaktike“. Navedimo, ipak, jedan primer. Princip VI glasi: „Priroda ne žuri, već ide polako“. Zatim sledi primer iz sveta prirode - ptičijeg sveta: „Ni ptica ne nosi jaja u vatru da bi brže izlegla mladunce, već ih postepeno zagreva prirodnom toplotom (...).“ Nakon toga sledi primer iz oblasti ljudskih veština - zanata: „Tako ni zidar ne diže suviše brzo zidove na temelju, ili krov na zidovima, jer nedovoljno isušen i učvršćen temelj obično popušta pod teretom..." (Komenski, 1954:124-125). Tek onda dolazi na red veština svih veština - nastava, kada se princip iz prirode (priroda ne žuri) primenjuje i u radu sa decom, i to tako što će se poštovati njihove uzrasne sposobnosti (time što se neće previše preopterećivati njihova pamet i previše zamarati preterenim brojem časova). 
Težnju za saznavanjem Komenski je smatrao konstitutivnim elementom ljudske prirode, dečje naročito, divio se dečjem duhovnom i telesnom dinamizmu i smatrao je da ne postoji ništa preteško i nedostupno dečjem saznanju, samo ako se koristi ispravna metoda i znanje prilagodi dečjem uzrastu. To se nigde ne vidi bolje nego u „Materinskoj školi“, gde on već za predškolski uzrast predlaže znanja iz ekonomije, politike, optike, astronomije i sl. Deluje prilično zastrašujuće. Međutim ne, astronomija se, na primer, svodi na razlikovanje Meseca, Sunca i zvezda, gde lakoća i shvatljivost u učenju proističu iz prilagođenosti, u ovom slučaju, predškolskom uzrastu (Spevak, 2003). Želja za znanjem i obrazovanjem, klica tog znanja, dati su ljudima samim rođenjem, ubeđen je Komenski. Otuda, ako se koristi dobar metod, čoveka, a decu posebno, nije potrebno terati da uče, isto kao što ,nije potrebno goniti pticu da nauči da leti, ribu da pliva, zver da trči“, ali „ni seme da klija kad je natopljeno vlagom i zagrejano toplotom (Komenski, 1954: 77). A dobar metod je prirodan, nenasilan, radostan, to je blago podsticanje i mudro upravljanje. Sve funkcioniše onako, kako je od prirode podešeno za rad i radi, ako mu se imalo pomogne. Svaka stvar dopušta da bude lako vođena onamo, kamo po prirodi naginje, ističe Komenski i citira Kvintilijana: „Želja za učenjem je u volji, koja se ne može prisiljavati“ (Komenski,1954:118). Učitelji zato treba da budu pristupačni i ljubazni (da ne odbijaju decu od učenja svojom mrgodnošću), kako bi im pridobili srce i kako bi deca rado boravila u školi, čak radije nego kod kuće. Odatle proističe, izričit je Komenski „da zbog učenja ne treba primenjivati nikakve batine" (Komenski, 1954: 127). A nad duševnim sposobnostima dece se vrši nasilje „ako ih gonimo da uče čemu njihove godine i moć shvatanja nisu dorasle“, ili ih primoravamo da pamte ili da rade nešto ,što im prethodno nismo u dovoljnoj meri objasnili, razvili ili osvetlili“" (Komenski, 1954: 126). Učitelj je sluga prirode, a ne njen gospodar, upozorava Komenski. U tom smislu, i priroda učenika je različita „te s ovim valja postupati ovako, a s drugim opet drugačije“ (Komenski, 1954: 165). Napomenimo da je već Kvintilijan, jedan od Komenskijevih uzora, govorio o individualnim razlikama među decom i neophodnosti da se one poštuju u nastavi. Priroda dece je različita, naglašava Komenski, kao što je različita i priroda biljaka, drveća, životinja. A ,gurati nekoga onamo kuda ga ne privlači priroda znači boriti se protiv prirode, a to je uzaludna muka" (Komenski, 1954: 165).

Komenski se u skladu s time ponašao u pedagoškoj praksi. U učionicu, među đake, nije ulazio s metlom, kako je bilo uobičajeno, nego ljubazno, s osmehom, pozivajući ih i mameći na avanturu saznavanja. Kako je to izrazio u „Materinskoj školi“: „Dođi, dečače, uči se mudrosti (...). Povešću te svuda, pokazaću ti sve, imenovaću ti sve" (Komenski, 2000:20). Strategije prisile, straha i kazni treba po Komenskom da budu zamenjene novim metodama, zasnovanim na poštovanju deteta, njegove ličnosti, njegove posebnosti i unutrašnje prirode, na primamljivosti, radosti i igri. Sa decom se „ne sme i ne može postupati kao sa stokom“ (Komenski,1992: 234). Dostojanstvo deteta se mora poštovati, učitelj ga u svom ponašanju mora pokazivati od najranijeg detinjstva. Komenski pristaje uz antički pedagoški princip maxima debetur 
puero reverentia parvo (,detetu smo obavezni najveće poštovanje“). Antika, odnosno humanizam i renesansa, a naročito Kvintilijanovi stavovi iz knjige „O obrazovanju govornika“, jesu bitan izvor Komenskijevih zahteva za blagošću, nenasilnošću, eliminisanjem neljudskih, ponižavajućih kaznenih postupaka. „U poučavanju omladine (...) upotrebljavan je tako surov metod da su škole smatrane uopšte kao strašila za decu i mučilišta za dušu“, ističe u „Velikoj didaktici“ (Komenski, 1954: 70). Najbolje svedočanstvo o sukobu sa uvreženim stavovima svoga vremena pruža boravak Komenskog u Blatnom Potoku od 1650-1654. godine, odnosno njegovo autobiografsko delo Continuatio admonitionis fraternae („Nastavak bratske opomene“), izdato 1669. godine u Amsterdamu, u kome beleži svoj sukob sa vlastima Ugarske, u pogledu odnosa prema deci i učenicima i neshvatanje njegovih metoda (osim ostalog i primene pozorišnih igara u nastavi): „Cela moja metoda ide ka tome da se školski rad pretvori u igru i radost, ovde to niko neće da shvati. Sa omladinom se postupa potpuno ropski, i sa plemićkom; učitelji grade svoj autoritet na namrgođenom licu, grubim rečima, čak i udarcima i radije žele da ih se boje, nego da ih vole“ (Molnar \& Rejchrtová, 1987: 238-239).

Uopšte, Komenski igri pridaje izuzetnu važnost, škola igrom je po njemu dobar naziv za celokupno ljudsko vaspitanje. Svaka škola po njegovom mišljenju može da postane središte igara, ako se poštuju prirodne težnje deteta, njegov prirodni razvoj, ako se u školi stvori atmosfera bez prisile, straha, blaga i stimulativna, gde se sve obavlja dobrovoljno i s radošću. Tada se stvaraju uslovi da princip igre, toliko značajan i deci imanentan, prožme duh škole. U spisu Schola ludus (,Škola igrom“), nastalom u Blatnom Potoku, a koja zapravo predstavlja pozorišnu adaptaciju njegovog čuvenog udžbenika za učenje jezika Janua linguarum reserata („Otvorena vrata jezika“), Komenski u uvodu daje veoma korektnu argumentaciju (pedagošku, psihološku, umetničku) u prilog korišćenja scenskih i pozorišnih (školskih) igara u nastavi, u njenom abecednom (čitanje i pisanje), likovnom, muzičkom, ali i fizikalnom, metafizičkom, moralnom, verskom, u celini pansofijskom aspektu (Spevak,2000).

\section{Omnia sponte fluant, absit violentia rebus (Neka sve teče spontano, bez nasilja)}

Mnogi autori isticali su da priroda i prirodnost čoveka imaju u vaspitnom sistemu Komenskog centralni položaj (Maňák, 1991). Prema Flosu, Komenskijevo omnia sponte fluant... je u tesnoj vezi sa njegovim univerzalnim svepopravnim konceptom, prema kome treba da budu odstranjeni svi oblici pritiska, koji ugnjetavaju ljudsku prirodnost (Floss, 2005, prema: Svoboda, 2010). Početak toga mora da bude već u vaspitanju u školi, koja treba da bude „radionica ljudskosti“. Absit violentia rebus (bez nasilja, neka stvarima odsustvuje nasilje) znači slobodu savesti i versku toleranciju. Komenski cilja na mirnu koegzistenciju naroda, država i konfesíja i, prema Flosu, time prevazilazi okvire ne samo svoje verske zajednice, nego i horizont reformacije 17. 
veka. Njegova pedagogija je u stvari sastavni deo filozofske koncepcije čoveka i istorije, kojom se Komenski konfrontira sa Augustinovom koncepcijom istorije (Floss, 2005, prema: Svoboda, 2010). Sagledavajući život čoveka (i) kroz sopstvenu prizmu, Komenski svet posmatra kao pun nesaglasnosti, nasilja i sukoba i otuda zahteva punu reformaciju ljudskog sveta, dakle čoveka kao pojedinca i društva kao celine. Primena univerzalne obrazovanosti je u osnovi postizanja saglasnosti/harmonije među narodima, državama i religijama i u tom cilju Komenski u „Konsultacijama“ predlaže osnivanje „Sabora svetla“ (Colegium lucis), koji bi takav zajednički obrazovni imenitelj obezbedio u evropskim/svetskim razmerama. Zbog ovakvih nastojanja Komenskog neretko nazivaju prvim pravim panevropljaninom (Svoboda, 2010).

Habl (Hábl, 2017) takođe naglašava fundamentalni značaj Komenskijevog motoa omnia sponte fluant, absit violentia rebus i njegovu povezanost sa idejom opšte harmonije. Stvari treba da budu i razvijaju se u skladu sa njihovim prirodnim karakterom, ističe Habl, a zatim upućuje na zaključke čuvenog češkog filozofa i komeniologa J. Patočku, koji upozorava da niko pre Komenskog nije u toj meri razvio ideju kreativne i sinergetičke uloge ljudske jedinke u zasnivanju onoga ars (veštine), o kome je bilo reči u prvom poglavlju, a čiji najviši izraz je upravo didaktika, kao poučavanje svih u svemu. Prema Patočki, Komenski nije odvajao ljudska bića od celine univerzuma, polazna tačka njegovih razmišljanja nije bilo izolovano ljudsko biće, ili čak njegov um (kako je to bilo kod R. Dekarta), nego univerzalna harmonija i povezanost svega sa svime. Ovaj češki filozof Komenskijev najznačajniji zavet i upozorenje za budućnost prepoznaje upravo u ovom momentu: sagledavanje realnosti kroz rascepljenu, čak neprijateljski suprostavljenu subjekt-objekt relaciju, gde je stvarnost fragmentizovana, a čovek bezobzirno egocentričan, gde je služenje celini stvarnosti potcenjeno, a princip kontrole i moći precenjen, razarajuće deluje na univerzalistički shvaćenu harmoniju (Patočka,1998).

Komenskijev moto omnia sponte fluant, absit violentia rebus, koje nalazimo na naslovnoj strani amsterdamskog izdanja njegovog spisa Opera didactica omnia (,Sabrani didaktiči spisi“), ali i na prednjim koricama drugih brojnih njegovih pedagoških dela, otkriva nam se, eto, u svojoj uzbudljivoj misaonoj višeslojnosti, dubini i svežini. Poreklo njegove savršene latinske forme klasičnog heksametra neki autori traže u Ovidijevim „Metamorfozama“, ali ujedno ističu da njegov doslovni uzor nikad nećemo otkriti, jer se kod Komenskog srećemo sa ogromnom erudicijom, kada je nemoguće naći sve konkretne književne izvore njegovih misli i formulacija (Maňák, 1991). Iako sadržaj ove slavne devize nije vezan isključivo za antiku, ona ipak verno izražava celokupnu atmosferu epohe renesanse (kojoj na polju vaspitanja odlučujući ton daje Kvintilijanovo delo „O obrazovanju govornika“, otkriveno 1413. godine), koja poštovanje prirode i prirodnosti preuzima od antike (Kato, Cicero, Seneka i dr.), za koju je, kao i za renesansu, priroda mera istinitosti, ishodište saznanja i vodilja života. Živeti u skladu s prirodom je najviša mudrost, tako olako i na duge staze zaboravljena. Kod Komenskog ova misao ima i hrišćanski ton, ponekad s verom obrazuje novu sinte- 
zu, ponekad, ipak ređe, u sukobu je sa njom, u svakom slučaju ostaje činjenica da su priroda i prirodnost čoveka temelj njegovog vaspitnog sistema. Ideja povezanosti prirodnosti sa nenasilnošću, spontanošću, samostalnošću prisutna je već u antici, ali je kod Komenskog prvi put izražena tako pregnantno, i tako opsežno obrazložena. Nakon njega, ideja prirodnosti, spontaniteta i slobode, koja vodi saznanju i radosti u dodiru s lepotom, odjeknuće snažno u snoviđenjima Ž. Ž. Rusoa, a biće prisutna i u samim temeljnim slojevima reformne pedagogije (Maňák, 1991).

$\mathrm{Na}$ odsjaj humanizma, renesanse i novih naučnih trendova njegove epohe na delo Komenskog ukazuje i Černa (Černá, 2019). Otkrivajući dubinske kulturno-istorijske korene Komenskijevog demokratizma i psiholoških anticipacija u tradicijama češke reformacije, husitizma i crkve Jedinstvo bratsko (Češka braća), kojoj je Komenski pripadao i na čelu koje je dugi niz godina bio (kao njen poslednji biskup), ali i uticaju naučnog pristupa prirodi F. Bekona, kao i snažnih impulsa T. Kampanele i njegovih pogleda na prirodu i čulnu osnovu saznanja, ova autorka naglašava svežinu i aktuelni značaj Komenskijevog kreda omnia sponte fluant... i njegovo naglašavanje da didaktičke metode treba da budu prirodne, nenasilne, u skladu sa postepenim mentalnim razvojem deteta. Ova autorka ukazuje da je čuveni razvojni psiholog Ž. Pijaže (J. Piaget) cenio i isticao psihološku vrednost Komenskijevih principa, kao što su: povezanost kognitivnih funkcija i aktivnosti, princip pozitivne i afektivne motivacije, princip postepenog razvoja, aspekti facilitacije/inhibicije obrazovnog procesa, princip saradnje učitelja i učenika (Černá, 2019). Inače Pijaže u svom tekstu iz 1957. godine, napisanog povodom 300 godina od prvog štampanja „Velike didaktike“ (Didactica magna) 1657. godine u Amsterdamu, visoko ceni Komenskijevu ideju prirodnosti, ističući da njegov genij leži upravo u činjenici da je obrazovanje shvatao kao samo jedan aspekt prirodne formativne mašinerije i da je integrisanost obrazovnog procesa u taj sistem kod njega uistinu suštinska. Pijaže centralnu ideju Komenskog, kada je reč o didaktici, vidi upravo u ideji prirodnog poretka. Taj poredak jeste osnovni princip obrazovanja i učitelj može da ostvari svoj zadatak samo ako ostane oruđe u rukama prirode. Obrazovanje je zbog toga integralni deo formativnog procesa, kome sva bića nužno podležu i ono je samo jedan aspekt tog procesa i razvoja (Piaget,1957).

Profesorica stokholmskog univerziteta A. Kraus Komenskog naziva ocem-osnivačem didaktike na Evropskom kontinentu i takođe ističe značaj njegove toliko naglašavane devize omnia sponte fluant..., koju prepoznaje kao odlučujuću za činjenicu, što su u kasnom 19. veku predstavnici reformne, pa i progresivne pedagogije Komenskog, uz Ž. Ž. Rusoa i J. H. Pestalocija, proglasili za svog misaonog lidera, koji je dete, njegovo samousmerenje, samoodređenje i samoaktivnost stavio u centar pedagogije (Kraus, 2018b). Njegova fundamentalna misao da sve teče samo od sebe i da je nasilje nepotrebno, odnosno da je spontana, samoodređena aktivnost, kreativnost i radoznalost dece polazna tačka učenja uopšte, inspirisala je mnoge kasnije pedagoge i čitave pokrete, a na tragu Komenskijevih razmišljanja, doduše bez eksplicitnog pominjanja hrišćanske vere, nekoliko progresivnih obrazovnih pristupa (Dž. Djui i mnogi dru- 
gi) početkom 20. veka je zagovaralo samoodređeno učenje, ističući eksperimentalno učenje kao najbolji metod (Kraus, 2018a). Komenski, uz već pominjane Rusoa i Pestalocija, ostvario je veliki uticaj na pokrete reformne pedagogije i ideje tzv. slobodnih škola tokom čitavog 20. veka širom Evrope. Jedna od takvih škola, nastala na inicijativu roditelja 1982. godine u Darmštadu u Nemačkoj (razredi od 1 - 10) nosi naziv „Slobodna škola Komenskog“ i uspešno funkcioniše kao javna škola. U njoj se primenjuju principi humanističke pedagogije i didaktike u tradiciji J. A. Komenskog (Kraus, 2018a).

\section{Zaključak}

Ove godine navršava se 350 godina od smrti teologa, filozofa i pedagoga J. A. Komenskog. Njegovo obimno i kompleksno delo još uvek je predmet živog naučnog interesovanja. Ako nekima možda ponekad izgleda prevaziđeno i pomalo „bajato“, što u nekim aspektima doduše i jeste istina, ipak je nepobitna činjenica da to delo (ponajviše upravo u njegovom pedagoškom i didaktičkom sloju), sadrži koncepte i pristupe, koji odišu neverovatnom svežinom i deluju inspirativno na sve one koji, u današnje vreme, tragaju za slobodnijim, humanijim, kreativnijim i autentičnijim didaktičkim i uopšte pedagoškim strategijama i metodama. Njegovo delo je (ponovo) otkriveno u 19. veku i od tada ne prestaje dinamična naučna komeniološka rasprava. Kroz nju su se iskristalisali veoma kompleksni i slojeviti misaoni elementi u Komenskijevom poimanju pedagoških i didaktičkih procesa, koji su na iznenađujući način obogatili savremene pedagoško-didaktičke rasprave. Njegova fundamentalna ideja prirodnosti, elegantno sažeta u latinskom heksametru omnia sponte fluant, absit violentia rebus, čijem razmatranju smo posvetili ovaj rad, bez sumnje je živa i danas i valja se na nju oslanjati u naučnom i emocionalnom nivou pedagoškog rada. Ona prožima sve slojeve humanističke pedagogije, didaktike, a posebno se koncentriše u odnosu prema centralnom pojmu i tački celokupnih vaspitno-obrazovnih usmerenja i nastojanja - detetu i detinjstvu kao takvom, dakle kao složenom, svakog poštovanja i pažnje vrednom kulturološko-društvenom konstruktu.

Kažimo sasvim na kraju da je Komenski bio čovek otvorenog uma, zahvaćen velikim oslobađanjem ljudske naučne misli u 17. veku i početkom epohe velikih naučno-tehnoloških otkrića. Naglašavao je da je sumnja, a ne puko saglašavanje uslov napretka, prihvatao je, radovao se i bio ponosan na napredak u nauci i tehnologiji, ali nikad nije odustajao od svoje univerzalističke, panharmonijske ideje, te je u skladu s time fomulisao i svoj odnos i prema ovoj temi: od nauke i tehnologije možemo mnogo toga dobiti, ali ako od njih očekujemo spas bićemo kao veverice zarobljene u kavezu od sopstvene ludosti (Černá, 2019). Izuzetna misao, dostojna ogromnih izazova 21. veka. 


\section{THE IDEA OF NATURALNESS - THE FUNDAMENTAL PRINCIPLE OF J. A. COMENIUS' DIDACTIC SYSTEM}

(on the occasion of the 350th anniversary of the death of the great pedagogue)

\section{Abstract}

In this paper the author sheds light on the fundamental idea of J. A. Comenius' didactic system which is the idea of naturalness. It was famously formulated by Comenius as omnia sponte fluant, absit violentia rebus loosely translated as "Let all things flow freely, let violence in all things be absent." The idea of naturalness has its roots in Comenius' panharmonious understanding of reality and his all-corrective striving: to repair each individual and society as a whole through true pansophic education. Comenius rejects all forms of violence including that in didactics - the art of teaching everything to all. Education and learning are parts of the natural flow and the teacher is a servant of nature, not its master. In accordance with that good methodology is natural, non-violent, joyous. The author points to deeper cultural and historical roots of Comenius'views (Hussite tradition and influences of F. Bacon, T. Campanella, M. F. Quintilian) as well as contemporary relevance of Comenius' didactic principles which influenced reformational as well as progressive pedagogy of the $20^{\text {th }}$ century. To this day these principles continue to inspire scientific and practical work in pursuit of a humane approach to learning and teaching that respects and encourages self-determination, self-initiative and the freedom and creativity of children.

Key words: Comenius, naturalness, didactics, reformational pedagogy, child.

\section{Literatura}

Černá, M.(2019). Johann Amos Comenius and His Legacy at the Information Age. In Cheung, S. K. S., Lee, L., Simonova, I., Kozel, T.\& Kwok, L. (Eds.),Blended Learning: Educational for Personalized Learning (pp. 46-59).Switzerland: SpringerInternational Publishing.

Hábl, J. (2017). Reformation and Education: Jan Amos Comenius's „Becoming Truly Human" and Reformation of Human Affairs. InBerthond, P. \& Lalleman, P. J. Eugen (Eds.),The Reformation. Its roots and Its Legacy(pp. 19-32). Oregon: Pickwick Publications.

Komenski, J. A. (1954). Velika didaktika. Beograd: Savez pedagoških društava Jugoslavije.

Komenski, J. A. (2000). Materinska škola. Beograd: Zavod za udžbenike i nastavna sredstva.

Komenský, J. A. (1992). Obecná porada o nápravě věcí lidských. Praha: Nakladatelství Sloboda. 
Kraus, A. (2018a). Sensitive Threshold - Awakening Aspects of the Corporeal-Auditive Reflexivity of Teenagers in the Classroom. InRodriguez Sieweke, L. (Ed.),Learning Scenarios for Social and Cultural Change: „Bildung “ through Academic Teaching (pp. 203-216). London\&New York: Peter Lang Publishing Group.

Kraus, A. (2018b). The Pupil in Didactics and the Practice Theory Approach. Retrieved September 2019 from https://www.diva-portal.org/smash/get/diva2:1179663/ FULLTEXT01.pdf

Maňák, J. (1991). Omnia sponte fluant, absit violentia rebus.Pedagogická orientace, $1(1), 43-48$.

Molnár, A.,\& Rejchrtová, N. (1987). Jan Amos Komenský o sobě. Praha: Odeon.

Patočka, J. (1981). Jan Amos Komenský. Bochum: Gessamelte Schriften zur Comenius forschung Veräffentlichungen. Der Comeniusforschungsstelle im Institut fiir Pädagogik der Rurh-Universität Bochum.

Patočka, J. (1998). Komeniologické studie 2:133. Prague: Oikoymenh.

Piaget, J. (1957). The significance of John Amos Comenius at the present time. Introduction to John Amos Comenius on education. Classics in Education series No.33, New York: Teachers College Press, Columbia University.

Spevak, Z. (2003). Jan Amos Komenski. Pedagog i utopista. Bački Petrovac, Novi Sad: Kultura, FORS.

Svoboda, J. (2010). Omnia sponte fluant...Studia Philosophica, 57(1), 163-168. 